\title{
Breastfeeding behavior is not associated with health literacy: evidence from the German KUNO-Kids birth cohort study
}

\author{
Teresa M. Graus ${ }^{1}$. Susanne Brandstetter ${ }^{2,3}$ - Birgit Seelbach-Göbel ${ }^{1} \cdot$ Michael Melter $^{2} \cdot$ Michael Kabesch $^{2,3}$. \\ Christian Apfelbacher ${ }^{4}$. Sara Fill Malfertheiner ${ }^{1,3}$ (1) $\cdot$ the KUNO-Kids study group
}

Received: 28 November 2020 / Accepted: 17 March 2021 / Published online: 27 April 2021

(c) The Author(s) 2021

\begin{abstract}
Purpose Despite the health benefits of full breastfeeding for both infants and mothers, less than $50 \%$ of mothers in Germany practice this method for at least 4 months after childbirth. Because of the growing importance of health literacy to improve public health, we investigated the role of maternal health literacy in breastfeeding behavior.

Methods We analyzed the data of 1172 mother-child dyads of the KUNO-Kids health study of the University Children's and Maternity Hospital Regensburg. Maternal health literacy was assessed with the HLS-EU-Q47 questionnaire (sub-index health care) up to $48 \mathrm{~h}$ after childbirth. Outcome was analyzed 6 months after childbirth and categorized into full breastfeeding for less than 4 months or for at least 4 months. The association between breastfeeding and maternal health literacy was calculated with univariable and multivariable logistic regression analyses.

Results $38.8 \%$ of mothers showed inadequate or limited health literacy. $75.9 \%$ of mothers had fully breastfed their child for at least 4 months. Univariable logistic regression analysis showed that health literacy and full breastfeeding for at least 4 months were not associated ( $\mathrm{OR}=0.995$ [CI 0.977-1.015], $p=0.60$ ). After adjusting for all potentially confounding variables with a significant association $(p \leq 0.05)$ on both health literacy and breastfeeding, the multivariable model showed no association between health literacy and breastfeeding ( $\mathrm{OR}=0.984$ [CI 0.963-1.007], $p=0.170$ ).

Conclusion Surprisingly, we found no association between health literacy and breastfeeding behavior in our study. Therefore, future research with comparable measurements of health literacy and breastfeeding is required to validate this result and to identify reasons for early breastfeeding cessation.
\end{abstract}

Keywords Health literacy $\cdot$ Health care $\cdot$ Breastfeeding $\cdot$ Breastfeeding promotion

\section{Abbreviation}

HL Health literacy

Sara Fill Malfertheiner

sara.fillmalfertheiner@barmherzige-regensburg.de

1 University Department of Gynecology and Obstetrics, Hospital St. Hedwig of the Order of St. John, University Medical Center Regensburg, Steinmetzstr., 1-3, 93049 Regensburg, Germany

2 University Children's Hospital Regensburg (KUNO), Hospital St. Hedwig of the Order of St. John, University of Regensburg, Steinmetzstr., 1-3, 93049 Regensburg, Germany

3 The Research and Development Campus Regensburg (WECARE), Hospital St. Hedwig of the Order of St. John, University of Regensburg, Regensburg, Germany

4 Institute of Social Medicine and Health Systems Research, Otto Von Guericke University Magdeburg, Leipziger Str. 44, 39120 Magdeburg, Germany

\section{Introduction}

Breastfeeding protects children from infections, improves cognitive development, and reduces the development of obesity, chronic diseases and even some types of cancer [1-5]. On top of improving a child's health, various positive gynecological outcomes have been described for mothers: a lower risk of developing diabetes, cardiovascular diseases, as well as ovarian and premenopausal breast cancer [6]. Nevertheless, up to 54\% of children in Germany are not fully breastfed for at least 4 months as recommended by the national commission for breastfeeding in Germany [7-9].

Multiple factors, such as breastfeeding problems or the educational status of the mother, may influence women's decisions not to breastfeed, which presents a potential risk to the development and health of the infants $[8,10]$. Besides other potential risk factors for premature weaning or the decision to never start breastfeeding at all, several studies 
have found that mothers with low health literacy (HL) are less likely to breastfeed their infants [11-15].

However, Mirjalili et al. did not find any association between HL and breastfeeding behavior in their Iranian study cohort [15]. Thus, scientific evidence on the association between HL and breastfeeding is contradictory.

In their 2030 Agenda for Sustainable Development established in November 2016, the Global Conference on Health Promotion emphasized the importance of facilitating the development of HL as "a critical determinant of health" [16]. In fact, according to the German Health Update study of 2013 (GEDA 2013s) with 4845 participants, $44.5 \%$ of German female habitants of childbearing age (between 18 and 39 years) have limited HL, which suggests that they have problems to find, understand, appraise, and apply information on health issues [17]. Limited HL impedes people's capability "to make judgments and take decisions in everyday life concerning healthcare, disease prevention, and health promotion to maintain or improve quality of life during the life course" [18]. Since its introduction in the 1970s, the concept of HL has gained importance worldwide. Thus, after the identification of this extensive HL deficit in Germany, a national action plan was launched in February 2018 to enhance HL in the German population [19, 20].

Women with a higher level of HL are likely to know more about the positive effects of breastfeeding, may have better strategies to solve problems, or may be more capable to reflect on their own behavior.

In view of the above-mentioned findings and the fact that more than $50 \%$ of the German population have limited HL, we investigated if the HL of mothers influence their breastfeeding behavior [21].

As far as we are aware, this is the first European study to investigate the association between HL and breastfeeding behavior. The analysis was based on data obtained from the large birth cohort study KUNO-Kids from Eastern Bavaria, Germany, to improve medical care in this patient population [22]. This investigation is highly relevant, particularly in view of the knowledge that adequate breastfeeding is one of the best strategies for disease prevention in both mothers and infants.

\section{Methods}

\section{Study design and setting}

We analyzed the data of the prospective multi-purpose KUNO-Kids health study on women who give birth in the Clinic St. Hedwig in Regensburg, Eastern Bavaria, Germany [22]. The Clinic St. Hedwig is a mother and child hospital affiliated with the University Medical Center Regensburg that counts approximately 3300 births per year [22].
Table 1 Follow-up rates of the study period

\begin{tabular}{llc}
\hline & $N$ & $\begin{array}{c}\text { \% of total } \\
N=2657\end{array}$ \\
\hline Baseline received & 2657 & 100.0 \\
4-week follow-ups received & 1647 & 62.0 \\
6-months follow-ups received & 1384 & 52.1 \\
Dyads with all three data sets & 1228 & 46.2 \\
\hline
\end{tabular}

Table 2 Number of mother-child dyads meeting the inclusion criteria

\begin{tabular}{lll}
\hline & $N$ & $\%$ of $N=1228^{\mathrm{a}}$ \\
\hline $\begin{array}{l}\text { No professionally diagnosed mastitis } \\
\begin{array}{l}\text { No drug intake incompatible with breastfeed- } \\
\text { ing }\end{array}\end{array}$ & 1173 & 95.5 \\
$\begin{array}{l}\text { Total number of includable cases for this } \\
\text { analysis }\end{array}$ & 1172 & 99.9 \\
\hline
\end{tabular}

${ }^{a}$ Number of mother-child dyads with all three data sets

The KUNO-Kids cohort comprises mother-child dyads who are prospectively studied by the following means: in hospital, mothers are interviewed and have to fill in questionnaires within 2 to 3 days after childbirth. Afterwards, a follow-up questionnaire is sent out 4 weeks and 6 months after childbirth and in every year until the child reaches 18 years of life.

\section{Participants and data collection}

As reported previously, mothers were asked to take part in the study within $48 \mathrm{~h}$ after giving birth [22]. They were given 1 day for consideration. Inclusion criteria for the KUNO-Kids health study were signed informed written consent of the mother, legal age, sufficient knowledge of the German language, and not participating in the study with another child.

The data for this analysis were obtained from personal interviews conducted by a study assistant at the clinic within 2 days after childbirth and from follow-up questionnaires sent out 4 weeks and 6 months after childbirth. Data of children born between June 2015 and September 2018 were collected. Table 1 shows the distribution of the received questionnaires for the various points in time.

Exclusion criteria of this analysis were multiple birth and the intake of medicine during pregnancy that is not recommended for being taken while breastfeeding. Furthermore, we excluded women with medically treated mastitis, assuming that they ceased breastfeeding because of this complication. Table 2 shows the number of women included after controlling for exclusion criteria. 


\section{Variables and measurement}

\section{Health literacy}

$\mathrm{HL}$ as the exposure of interest is investigated by means of the sub-index health care of the standardized and validated HLS-EU-Q47 questionnaire. This questionnaire is measured as a multidimensional 12-cell matrix with questions combining each of the four key processes of accessing, understanding, appraising, and applying health-related information [23]. Each of the 16 questions on health care, investigated by means of the interview could be answered with "very difficult", "rather difficult", "rather easy", or "very easy" on a four-point Likert-type scale. The interview included questions, such as "How difficult/easy is it for you to find information on symptoms you have developed?" or "How difficult/easy is it for you to find out if information on your illness in the media is reliable?" The health care HL index results in a score ranging between 0 and 50. For the sample description, the scores were categorized into four levels: "inadequate" (0-25), "problematic" (> 25-33), "sufficient" (>33-42) and "excellent" (>42-50) [23, 24]. Scores in the regression analyses were used as continuous variables.

\section{Full breastfeeding}

The investigation's outcome was the rate of full breastfeeding 4 months after childbirth that was investigated by means of the interview's question "Do you breastfeed your child?" and the 6-month follow-up question "How long did you breastfeed your child without giving any complementary food?". Full breastfeeding in this context means, that the child only received breast milk but no formula or complementary food. We dichotomized full breastfeeding into less than 4 months and at least 4 months after childbirth.

\section{Confounders}

The following variables were considered as potential confounders.

Age, parity, and the marital status of the mother were assessed by means of direct questions during the interview.

The educational level was categorized according to the "Comparative Analysis of Social Mobility in Industrial Nations (CASMIN)" classification in the latest version, including education and vocational education, in "low" (CASMIN 1), "moderate" (CASMIN 2) and "high" (CASMIN 3) [25, 26].

Migration background was indexed on the basis of the country of birth of the mother or her parents outside Germany.

Maternal smoking was documented, if the mother had smoked or had consumed alternative smoking products during pregnancy or smoked regularly after childbirth, and this aspect was investigated within the 4-week follow-up.

The mother's health-related quality of life was quantified by means of the Short Form Health Survey Questionnaire (SF-12) [27]. Quality of life was measured using the two subscales of the questionnaire, i.e. physical health (PSC) and mental health (MCS). Each subscale may yield values between 0 and 100 [28].

The body mass index in $\mathrm{kg} / \mathrm{m}^{2}$ prior to pregnancy was calculated in accordance with the values for height and weight given in the personal interview. Physical activity prior to pregnancy was categorized according to the recommendation of the World Health Organization of not less than $2.5 \mathrm{~h}$ of physical activity per week and during pregnancy according to the recommendation of the German Association for Sports Medicine and Prevention of 1-2 $h$ of physical activity per week $[29,30]$. Hence, the information about physical activity before and during pregnancy obtained in the interview was scaled in "less than recommended", "as recommended" or "more than recommended". The 4-week follow-up also included questions about alcohol consumption before and during pregnancy as well as after childbirth. Alcohol consumption of the mother was evaluated according to the number of standard alcoholic drinks per week and was categorized as risky if the amount of alcoholic drinks was six or more per week in the year prior to pregnancy or if the mother had consumed any alcohol during pregnancy and lactation [31].

The 6-month follow-up included questions on the mother's occupation between giving birth and 6 months after childbirth.

A German version of the MacArthur Scale was used to measure the mother's subjective social status at the 4-week follow-up. Using an imaginary ladder with 10 rungs, the participants had to rate their personal social status as compared to their community members between 0 (least money, lowest education, and worst jobs) and 10 (most money, highest education, and best jobs) [32].

Midwife service was assessed at the 6-month follow-up.

\section{Statistical analysis}

To describe the sample's socio-demographic data, we calculated means with standard deviations for continuous data and frequencies with percentages for categorical data. The duration of full breastfeeding in weeks is presented using mean with standard deviation, and the outcome variable full breastfeeding for at least 4 months is presented using frequency with percentage.

Univariable logistic regression analysis was used to evaluate the association between the HL index as a metric scale and full breastfeeding for less than 4 months vs. for at least 4 months. Additionally, multivariable logistic regression 
analysis was used to control for confounders that showed a statistically significant association $(p \leq 0.050)$ in univariable analysis for both the HL index and breastfeeding.

Statistical analyses were done with IBM SPSS.23.

\section{Results}

This analysis included 2657 mother-child dyads. All participants in the first assessment were invited to participate in the follow-up assessments. Therefore, longitudinal analyses after 6 months were possible for 1228 dyads (Table 1 ). Finally, 1172 mother-child dyads met the inclusion criteria (Table 2).

$38.8 \%$ of mothers showed inadequate or limited HL, whereas $18.5 \%$ had an excellent HL level. $75.9 \%$ of mothers fully breastfed their child for at least 4 months and the mean duration of full breastfeeding in the study population was 16.4 weeks. The characteristics of the study population are shown in Table 3.
Univariable logistic regression analysis showed that the HL index and full breastfeeding for at least 4 months were not significantly associated [odds ratio (OR): $0.995,95 \%$ confidence interval (95\% CI) [0.977-1.015], $p=0.600$, $N=1094]$. This finding did not change after adjusting for parity, marital status, maternal education, SF-12 MCS, physical activity during pregnancy, subjective social status, and midwife service (OR: 0.986 CI [0.964-1.008], $p=0.218$, $N=964)$. The discrepancy between the total numbers stated is due to missing data for items that were relevant for the logistic regression analyses.

\section{Discussion}

Surprisingly, we did not find any positive association between the HL level of mothers and their breastfeeding behavior when considering breastfeeding for at least 4 months versus less than 4 months after childbirth. This finding is not in line with the extant literature on this topic.
Table 3 Socio-demographic characteristics of the sample

\begin{tabular}{|c|c|c|}
\hline & $N^{\mathrm{a}}($ total $N=1172)$ & Value \\
\hline Duration of pregnancy (weeks) $M(\mathrm{SD})$ & 1164 & $39.58(1.58)$ \\
\hline Preterm births ( $\leq 36+6$ gestational weeks, $M=35.37) N(\%)$ & & $68(5.84)$ \\
\hline Infant's sex (female) $N(\%)$ & 1172 & $588(50.2)$ \\
\hline Maternal age (years) $M(\mathrm{SD})$ & 1161 & $34.56(4.26)$ \\
\hline Birth mode (cesarean section) $N(\%)$ & 1172 & $319(27.2)$ \\
\hline Parity (two or more children) $N(\%)$ & 1164 & $474(40.7)$ \\
\hline Marital status of the mother & 1157 & \\
\hline Married $N(\%)$ & & $948(81.9)$ \\
\hline Unmarried but living together with a partner $N(\%)$ & & $193(16.7)$ \\
\hline Unmarried without a partner, divorced, or widowed $N(\%)$ & & $16(1.4)$ \\
\hline Maternal education & 1145 & \\
\hline CASMIN 1 [elementary education] $N(\%)$ & & $80(7.0)$ \\
\hline CASMIN 2 [intermediate education] $N(\%)$ & & $512(44.7)$ \\
\hline CASMIN 3 [tertiary education] $N(\%)$ & & $553(48.3)$ \\
\hline Maternal migration background $N(\%)$ & 1100 & $180(16.4)$ \\
\hline Maternal smoking $N(\%)$ & 1159 & $43(3.7)$ \\
\hline Health literacy (HLS-EU sub-index health care) $M(\mathrm{SD})$ & 1143 & $35.30(7.21)$ \\
\hline Inadequate $\left(0-25^{\mathrm{b}}\right) N(\%)$ & & $87(7.6)$ \\
\hline Limited $\left(>25-33^{\mathrm{b}}\right) N(\%)$ & & $357(31.2)$ \\
\hline Sufficient $\left(>33-42^{\mathrm{b}}\right) N(\%)$ & & $488(42.7)$ \\
\hline Excellent $N\left(>42-50^{\mathrm{b}}\right)(\%)$ & & $211(18.5)$ \\
\hline Breastfeeding at hospital discharge $N(\%)$ & 1158 & $1018(87.9)$ \\
\hline Full breastfeeding for at least 4 months $N(\%)$ & 1079 & $819(75.9)$ \\
\hline Duration of full breastfeeding ${ }^{\mathrm{c}}$ (weeks) $M(\mathrm{SD})$ & & $16.40(9.27)$ \\
\hline
\end{tabular}

$N$ number of women's answers regarding the individual item, $M$ mean value, $S D$ standard deviation

${ }^{a}$ The difference between the total numbers is due to missing data for this specific item

${ }^{\mathrm{b}} \mathrm{Score}$ ranges of the HL index regarding the specific level

${ }^{\mathrm{c}}$ As assessed in the 6-months questionnaire 
Comparability to other studies is limited because of the widely varying measurement of HL and the inconsistent definitions of the outcome breastfeeding. Yin et al., Stafford et al., and Kaufman et al. quantified HL by means of questionnaires that exclusively measured functional $\mathrm{HL}$ in their study populations: Short Test of Functional Health Literacy in Adults (S-TOFHLA) [Yin and Stafford] or Rapid Estimates of Adult Literacy in Medicine (REALM) [Kaufman]. REALM measures the reading and pronunciation ability of medical words and texts only, whereas S-TOFLA also integrates comprehension of the terms [11, 12, 14, 33]. All authors found positive correlations between HL and breastfeeding behavior, although the outcome breastfeeding was assessed differently in each study: feeding of a higher proportion of breastmilk than formula [Yin], a higher rate of exclusive breastfeeding shortly after birth [Stafford], and exclusive breastfeeding for more than 2 months [Kaufman] $[11,12,14]$. Vila-Candel et al. found no statistical significant association between functional HL measured by newest vital sign (NVS) and exclusive breastfeeding for more than 4 months [34].

Using the Iranian questionnaire HELIA (Health Literacy Instrument for Adults), Hosseini et al. and Mirjalili et al. assessed HL more comprehensively and included accessing, understanding, evaluating, and applying of health-related information [13, 15, 35, 36]. Inconsistent assessment of breastfeeding should also be noticed: breastfeeding duration in general [Hosseini] and breastfeeding patterns that aim at the proportion of breastmilk in contrast to formula feeding [Mirjalili] [13, 15]. Only the results of Mirjalili et al. were in line with ours, as these authors did also not find any statistically significant association between HL and breastfeeding [15].

We chose a subscale of the HLS-EU, the most extensive instrument established so far, which assesses "all areas of health literacy [in combination with] social determinants of health", such as social support or accessibility to health care services [37]. It measures not only individual skills but also "the self-experienced and self-rated relation or fit of personal competencies and situational demands/complexity" $[38,39]$. Jordan et al. and Freedman et al. emphasized that additional environmental influences, such as social, socioeconomic, or healthcare-related issues, may mitigate the ability to deal with health information [40,41]. It is remarkable that our study's broader assessment of HL led to a different result than solely assessing (functional) HL.

A mother's decision to breastfeed could be based on socio-cultural reasons or on model learning from their relatives or peers, which may also predominate the decision on the duration of breastfeeding. Kohlhuber et al., for example, identified the attitudes of the partner and the maternal grandmother towards breastfeeding as an influencing factor for the duration of breastfeeding [42].
Moreover, the recent SuSe II study has shown that health education on breastfeeding is more and more implemented in birth clinics throughout Germany, for example, by means of prenatal classes and midwife support [43]. Hence, mothers may develop better breastfeeding behavior because of this specific support, independent of individual HL levels.

Nevertheless, to improve breastfeeding rates, it seems relevant to further strengthen specifically tailored programs for breastfeeding promotion, such as targeted information about breastfeeding, breastfeeding instructions, and incorporation in the social environment.

\section{Strengths and limitations}

The initial breastfeeding rate of $87.9 \%$ found in our study was rather similar to the rate of $87.3 \%$ described in the German KiGGS study (study on the health of children and adolescents in Germany) (birth cohort 2013/2014) [9]. The full breastfeeding rate of $75.9 \%$ for 4 months after childbirth in our study was much higher than the rate of $46.0 \%$ in the KIGGs study (birth cohort 2009-2014) and the rate of $60.1 \%$ in the SuSe II study (birth cohort January-March 2018) $[9,43]$. The high breastfeeding rate in our sample may be due to the inclusion of mother-child dyads in a prospective study design. In contrast to cross-sectional analyses of breastfeeding rates in studies, such as KIGGs or SuSe II, the loss to follow-up in our study could lead to the exclusion of a disproportionately high percentage of women who did not intend to breastfeed according to the recommendation. This attrition bias has been described in a Bavarian cohort study by Kohlhuber et al. [42].

In the KUNO Kids study, selection bias is likely because more mothers with a higher education level were inclined to take part in the study. In our population, a clear shift towards higher education could be stated in comparison to the 2004 data of the German population (age cohort 25-44 years) that showed a low education level (CASMIN 1) of $30.4 \%$, a mideducation level (CASMIN 2) of 51.4\%, and a high education level (CASMIN 3) of 14.8\% [44].

Factors positively influencing breastfeeding behavior in relation to our study's inclusion bias were the large proportion of highly educated mothers, the above-average social status, the low percentage of critically ill or premature infants, and the study site in a region that previously constituted West Germany, for which Lange et al. had described longer durations of full breastfeeding $[8,32,45]$. Moreover, we excluded mothers with professionally diagnosed mastitis, which is a relevant factor for early breastfeeding cessation [46].

It should be noted, that, for feasibility reasons, we assessed the sub-index health care rather than the entire HLS-EU-Q47 instrument. Nevertheless, Pelikan et al. described a high intercorrelation between the three 
sub-indices health care, disease prevention, health promotion, and general HL by measuring HL with the HLS-EU instrument [38].

Our study shows a lower proportion of mothers with limited and inadequate HL compared to the general German population (38.8\% vs. $44.2 \%$ ) [17]. This difference may be explained by the age distribution (19-46 years) and the high percentage of highly educated mothers, as both factors are associated with higher HL levels [47].

However, it should be mentioned that HLS-EU items were recorded by means of personal interviews in the presence of a study assistant which may lead to higher HL levels in the context of social desirability.

Nevertheless, the proportion of $38.8 \%$ of women with an insufficient HL level seems to be disappointing at first sight. However, one needs to bear in mind that the German Health Literacy Survey using the HLS-EU-Q47 questionnaire yielded a prevalence of limited HL of $>50 \%$, even in people with an intermediate or high level of education [21]. This result as well as our findings needs to be interpreted in consideration of the nature of the HLS-EU questionnaire that asks people to self-assess personal difficulties regarding health issues. Even educated people may report difficulties in finding information on their symptoms or in assessing the reliability of information on one's illness in the media. An educational reflection on the items presented in the questionnaire may even lead to endorsing more rather than less difficulty.

Obvious strengths of the KUNO-Kids study are its large number of participants of more than 1000 mother-child dyads and its design as a longitudinal cohort study. Furthermore, the Clinic St. Hedwig as Bavaria's largest perinatal center with patients from urban, suburban, and rural areas provides a good mixture of study participants despite its slightly increased rate of high-risk deliveries [22]. Using items from internationally and nationally validated questionnaires to investigate selected maternal psychosocial characteristics (e.g. CASMIN, HLS-EU, and SF-12) guarantees comparability with other studies.

\section{Conclusion}

The missing association between breastfeeding and HL may be explained by multiple aspects as outlined above. Only a few comparable studies have been published so far. Thus, further studies using comparable measurement methods of $\mathrm{HL}$ and breastfeeding are required to objectify relevant factors associated with breastfeeding to develop specific programs for breastfeeding initiation and adherence and to reduce the burden for health-care systems by improving preventive actions.
Acknowledgements We thank all members of the KUNO-Kids study group: A. Ambrosch (Institute of Laboratory Medicine, Microbiology and Hygiene, Barmherzige Brüder Hospital, Regensburg), P. Arndt (ZNL Transfercenter of Neuroscience and Learning, University of Ulm), A. Baessler (Department of Internal Medicine II, Regensburg University Medical Center), M. Berneburg (Department of Dermatology, University Medical Center Regensburg), St. Böse-O'Reilly (Institute and Clinic for Occupational, Social and Environmental Medicine, University Hospital, LMU Munich), R. Brunner (Clinic of Child and Adolescent Psychiatry, Psychosomatics and Psychotherapy, Bezirksklinikum Regensburg), Wolfgang Buchalla (Department of Conservative Dentistry and Periodontology, University Hospital Regensburg), A. Franke (Institute of Clinical Molecular Biology, Christian-AlbrechtsUniversity of Kiel), S. Häusler (Clinic of Ob\&Gyn St. Hedwig, University of Regensburg), I. Heid (Department of Genetic Epidemiology, University of Regensburg), C. Herr (Bavarian Health and Food Safety Authority (LGL), Munich), W. Högler (Department of Pediatrics and Adolescent Medicine, Johannes Kepler University Linz), S. Kerzel (Department of Pediatric Pneumology and Allergy, University Children's Hospital St. Hedwig Regensburg), M. Koller (Center for Clinical Studies, University Hospital Regensburg), M. Leitzmann (Department of Epidemiology-Preventive Medicine, University of Regensburg), D. Rothfuß (Coordinating Center for Early Interventions, Regensburg), W. Rösch (Department of Pediatric Urology, University Medical Center, Regensburg), B. Schaub (Pediatric Allergology, Dr. von Hauner Children's Hospital, LMU Munich), B. H. F. Weber (Institute of Human Genetics, University of Regensburg), St. Weidinger (Department of Dermatology, Venereology and Allergy, University Hospital Schleswig-Holstein Kiel) and S. Wellmann (Children's Hospital St. Hedwig, University of Regensburg). Further, we sincerely thank M. Schöll (Center for Clinical Studies, University Hospital Regensburg) for the linguistic revision of our manuscript.

Author contributions TMG: project development, data collection and analysis, data interpretation, manuscript writing. SB: study design, data analysis, manuscript editing and approval. BSG: data collection, manuscript approval. MM: data collection, manuscript approval. MK: study design, project development, data collection, manuscript approval. CA: data interpretation, manuscript editing and approval. SFM: project development, study design, data collection, manuscript editing and approval.

Funding Open Access funding enabled and organized by Projekt DEAL. The KUNO-Kids study is funded by research grants of the EU (HEALS: 603946) and the German Federal Ministry for Education and Research (SYSINFLAME: 01ZX1306E). Further financial support was provided by the University Children's Hospital of the University of Regensburg (KUNO-Clinics) and the Hospital St. Hedwig of the Order of St. John. The funding bodies had neither influence on the design of the study, the collection, analysis and interpretation of the data, nor on the writing of the manuscript.

Availability of data and materials The datasets used and/or analyzed for this paper are available from the corresponding author on reasonable request.

\section{Declarations}

Conflict of interests All authors declare that they have no conflict or competing interests.

Ethics approval and consent to participate The study was approved by the Ethics Committee of the University of Regensburg (file number: 14-101-0347). All participating parents provide written informed con- 
sent. The consent procedure that reflects all data sources and assessment methods is continuous over the course of the study so that participants are asked at each follow-up if they will participate in the next follow-up. Furthermore, it provides the option of consenting to certain elements of the study while refusing consent to others (e.g., consenting to complete self-report questionnaires). The participants have the right to withdraw from the study at any time.

Open Access This article is licensed under a Creative Commons Attribution 4.0 International License, which permits use, sharing, adaptation, distribution and reproduction in any medium or format, as long as you give appropriate credit to the original author(s) and the source, provide a link to the Creative Commons licence, and indicate if changes were made. The images or other third party material in this article are included in the article's Creative Commons licence, unless indicated otherwise in a credit line to the material. If material is not included in the article's Creative Commons licence and your intended use is not permitted by statutory regulation or exceeds the permitted use, you will need to obtain permission directly from the copyright holder. To view a copy of this licence, visit http://creativecommons.org/licenses/by/4.0/.

\section{References}

1. Martin RM, Gunnell D, Owen CG et al (2005) Breast-feeding and childhood cancer: a systematic review with metaanalysis. Int J Cancer 117:1020-1031. https://doi.org/10.1002/ijc.21274

2. Vieira Borba V, Sharif K, Shoenfeld Y (2018) Breastfeeding and autoimmunity: programing health from the beginning. Am J Reprod Immunol. https://doi.org/10.1111/aji.12778

3. Redsell SA, Edmonds B, Swift JA et al (2016) Systematic review of randomised controlled trials of interventions that aim to reduce the risk, either directly or indirectly, of overweight and obesity in infancy and early childhood. Matern Child Nutr 12:24-38. https:// doi.org/10.1111/mcn.12184

4. Angelsen NK, Vik T, Jacobsen G et al (2001) Breast feeding and cognitive development at age 1 and 5 years. Arch Dis Child 85:183-188. https://doi.org/10.1136/adc.85.3.183

5. Duijts L, Ramadhani MK, Moll HA (2009) Breastfeeding protects against infectious diseases during infancy in industrialized countries. A systematic review. Matern Child Nutr 5:199-210. https:// doi.org/10.1111/j.1740-8709.2008.00176.x

6. Binns C, Lee M, Low WY (2016) The long-term public health benefits of breastfeeding. Asia Pac J Public Health 28:7-14. https://doi.org/10.1177/1010539515624964

7. Bundesinstitut für Risikobewertung (2020) Empfehlungen zur Stilldauer - Einführung von Beikost (Recommendation for breastfeeding duration and introduction of complementary food). https://www.bfr.bund.de/de/empfehlungen_zur_stilldauer__einfu ehrung_von_beikost-54044.html. Accessed 29 June 2020

8. von der Lippe E, Brettschneider A-K, Gutsche J et al (2014) Einflussfaktoren auf Verbreitung und Dauer des Stillens in Deutschland: Ergebnisse der KiGGS-Studie - Erste Folgebefragung (KiGGS Welle 1) (Factors influencing the prevalence and duration of breastfeeding in Germany: results of the KiGGS study: first follow up (KiGGS Wave 1)). Bundesgesundheitsblatt Gesundheitsforschung Gesundheitsschutz 57:849-859. https://doi. org/10.1007/s00103-014-1985-5

9. Brettschneider A-K, von der Lippe E, Lange C (2018) Stillverhalten in Deutschland - Neues aus KiGGS Welle 2 (Breastfeeding behaviour in Germany-News from KiGGS Wave 2). Bundesgesundheitsblatt Gesundheitsforschung Gesundheitsschutz 61:920925. https://doi.org/10.1007/s00103-018-2770-7
10. Gerd A-T, Bergman S, Dahlgren J et al (2012) Factors associated with discontinuation of breastfeeding before 1 month of age. Acta Paediatr 101:55-60. https://doi.org/10.1111/j.1651-2227.2011. 02405.x

11. Kaufman H, Skipper B, Small L et al (2001) Effect of literacy on breast-feeding outcomes. South Med J 94:293-296. https://doi. org/10.1097/00007611-200103000-00005

12. Yin HS, Sanders LM, Rothman RL et al (2014) Parent health literacy and "obesogenic" feeding and physical activity-related infant care behaviors. J Pediatr 164:577-83.e1. https://doi.org/ 10.1016/j.jpeds.2013.11.014

13. Hosseini F, Rasekhi A, Lamyian M (2019) Investigating the relationship between breastfeeding duration and health literacy in Primiparous women referring to Tehran health centers an application of Bayesian Poisson regression model. J Biostat Epidemiol 5:12-17. https://doi.org/10.18502/jbe.v5i1.1902

14. Stafford JD, Lathrop E, Haddad L (2016) Health literacy and associated outcomes in the postpartum period at Grady memorial hospital [2H]. Obstet Gynecol 127:66S-67S. https://doi.org/ 10.1097/01.AOG.0000483913.45246.45

15. Mirjalili N, Ansari Jaberi A, Ansari Jaberi K et al (2018) The role of maternal health literacy in breastfeeding pattern. J Nurs Midwifery Sci 5:53. https://doi.org/10.4103/JNMS.JNMS_21_ 18

16. World Health Organization (2016) Shanghai declaration on promoting health in the 2030 agenda for sustainable development: proceedings of 9th global conference on health promotion

17. Jordan S, Hoebel J (2015) Gesundheitskompetenz von Erwachsenen in Deutschland: Ergebnisse der Studie "Gesundheit in Deutschland aktuell" (GEDA) (health literacy of adults in Germany: findings from the German health update (GEDA) study). Bundesgesundheitsblatt Gesundheitsforschung Gesundheitsschutz 58:942-950. https://doi.org/10.1007/s00103-015-2200-z

18. Sørensen K, van den Broucke S, Fullam J et al (2012) Health literacy and public health: a systematic review and integration of definitions and models. BMC Public Health 12:80. https://doi.org/ 10.1186/1471-2458-12-80

19. Simonds SK (1974) Health education as social policy: professor of health education university of Michigan, school of public health. Health Educ Monogr 2:1-10. https://doi.org/10.1177/1090198174 0020S 102

20. Schaeffer D, Hurrelmann K, Bauer U Kolpatzik K (2018) Nationaler Aktionsplan Gesundheitskompetenz: Die Gesundheitskompetenz in Deutschland stärken. (National Action Plan for Health Literacy). KomPart

21. Schaeffer D, Berens E-M, Vogt D (2017) Health literacy in the German population. Dtsch Arztebl Int 114:53-60. https://doi.org/ 10.3238/arztebl.2017.0053

22. Brandstetter S, Toncheva AA, Niggel J et al (2019) KUNO-Kids birth cohort study: rationale, design, and cohort description. Mol Cell Pediatr 6:1-10. https://doi.org/10.1186/s40348-018-0088-z

23. Sørensen K, van den Broucke S, Pelikan JM et al (2013) Measuring health literacy in populations: illuminating the design and development process of the European health literacy survey questionnaire (HLS-EU-Q). BMC Public Health 13:948. https://doi. org/10.1186/1471-2458-13-948

24. Sørensen K, Pelikan JM, Röthlin F et al (2015) Health literacy in Europe: comparative results of the European health literacy survey (HLS-EU). Eur J Public Health 25:1053-1058. https://doi.org/10. 1093/eurpub/ckv043

25. Brauns H, Scherer S, Steinmann S (2003) The CASMIN educational classification in international comparative reasearch. In: Hoffmeyer-Zlotnik JWC (ed) Advances in cross-national comparison: a European working book for demographic and socioeconomic variables. Kluwer Academic/Plenum Publisher, New York, pp 221-244 
26. Pförtner T-K, Elgar FJ (2016) Widening inequalities in self-rated health by material deprivation? A trend analysis between 2001 and 2011 in Germany. J Epidemiol Community Health 70:82-89. https://doi.org/10.1136/jech-2015-205948

27. Wirtz MA, Morfeld M, Glaesmer H et al (2018) Normierung des SF-12 Version 2.0 zur Messung der gesundheitsbezogenen Lebensqualität in einer deutschen bevölkerungsrepräsentativen Stichprobe (Standardization of the SF-12 version 2.0 to measure health-related quality of life in a German population-representative sample). Diagnostica 64:215-226. https://doi.org/10.1026/ 0012-1924/a000205

28. Ware JE, Kosinski M, Keller SD (1996) A 12-item short-form health survey: construction of scales and preliminary tests of reliability and validity. Med Care 34:220-233

29. World Health Organization (2010) Global recommendations on physical activity for health. https://apps.who.int/iris/bitstream/ handle/10665/44399/9789241599979_eng.pdf;jsessionid=9D287 34153768063 D7D0F4CB1D8BB08C? sequence $=1$. Accessed 30 June 2020

30. Korsten-Reck U, Marquardt K, Wurster KG (2009) Schwangerschaft und sport: pregnancy and sports. Deutsche Zeitschrift für Sportmedizin 60:117-121

31. Bundeszentrale für gesundheitliche Aufklärung Alkohol? Kenn dein Limit. (Federal Centre for Health Education-Alcohol? Know your limit). https://www.kenn-dein-limit.de/. Accessed 24 May 2020

32. Hoebel J, Müters S, Kuntz B et al (2015) Messung des subjektiven sozialen status in der Gesundheitsforschung mit einer deutschen version der MacArthur Scale (Measuring subjective social status in health research with a German version of the MacArthur Scale). Bundesgesundheitsblatt Gesundheitsforschung Gesundheitsschutz 58:749-757. https://doi.org/10.1007/s00103-015-2166-x

33. Baker DW, William MV, Parker RM (1999) Development of a brief test to measure functional health literacy. Patient Educ Couns 38:33-42

34. Vila-Candel R, Soriano-Vidal FJ, Mena-Tudela D et al (2020) Health literacy of pregnant women and duration of breastfeeding maintenance: a feasibility study. J Adv Nurs. https://doi.org/10. $1111 /$ jan. 14625

35. Montazeri A, Tavousi M, Rakhshani F et al (2014) Health literacy for Iranian adults (HELIA): development and psychometric properties. Payesh 13:589-599

36. Tavousi M, Haeri-Mehrizi A, Rakhshani F et al (2020) Development and validation of a short and easy-to-use instrument for measuring health literacy: the health literacy instrument for adults (HELIA). BMC Public Health 20:656. https://doi.org/10.1186/ s12889-020-08787-2

37. Tavakolikia N, Kheiltash A, Shojaeefar E et al (2017) The most well-known health literacy questionnaires: a narrative review. Soc Determinants Health 3:104-113
38. Pelikan JM, Röthlin F, Ganahl K, in behalf of the consortium of the HLS-EU project (2012) Comparative report of health literacy in eight EU Member States. The European health literacy survey HLS-EU (Second revised and extended version, date July 22th, 2014)

39. Parker R (2009) Measuring health literacy: What? So what? Now what? In: Hernandez LM (ed) Measures of health literacy: workshop summary, vol 6. National Academies Press, Washington D.C., pp 91-98

40. Jordan JE, Buchbinder R, Osborne RH (2010) Conceptualising health literacy from the patient perspective. Patient Educ Couns 79:36-42. https://doi.org/10.1016/j.pec.2009.10.001

41. Freedman DA, Bess KD, Tucker HA et al (2009) Public health literacy defined. Am J Prev Med 36:446-451. https://doi.org/10. 1016/j.amepre.2009.02.001

42. Kohlhuber M, Rebhan B, Schwegler U et al (2008) Breastfeeding rates and duration in Germany: a Bavarian cohort study. Br J Nutr 99:1127-1132. https://doi.org/10.1017/S0007114508864835

43. Kersting M, Hockamp N, Burak C et al (2020) Studie zur Erhebung von Daten zum Stillen und zur Säuglingsernährung in Deutschland - SuSe II (Study about breastfeeding and infant feeding in Germany - SuSe II): Deutsche Gesellschaft für Ernährung (ed): 14. DGE-Ernährungsbericht. Vorveröffentlichung Kapitel 3. Bonn V1-V34. http://www.dge.de/14-dge-eb/vvoe/kap3

44. Lechert Y, Schroedter J, Lüttinger P (2006) ZUMA-Methodenbericht 2006/12: Die Umsetzung der Bildungsklassifikation CASMIN für die Volkszählung 1970, die Mikrozensus- Zusatzerhebung 1971 und die Mikrozensen 1976-2004

45. Lange C, Schenk L, Bergmann R (2007) Verbreitung, Dauer und zeitlicher Trend des Stillens in Deutschland. Ergebnisse des Kinder- und Jugendgesundheitssurveys (KiGGS) (Distribution, duration and temporal trend of breastfeeding in Germany. Results of the German Health Interview and Examination Survey for Children and Adolescents (KiGGS)). Bundesgesundheitsblatt Gesundheitsforschung Gesundheitsschutz 50:624-633. https://doi. org/10.1007/s00103-007-0223-9

46. Odom EC, Li R, Scanlon KS et al (2013) Reasons for earlier than desired cessation of breastfeeding. Pediatrics 131:726-732. https://doi.org/10.1542/peds.2012-1295

47. Brandstetter S, Atzendorf J, Seelbach-Göbel B et al (2020) Sociodemographic factors associated with health literacy in a large sample of mothers of newborn children: cross-sectional findings from the KUNO-Kids birth cohort study. Eur J Pediatr 179:165169. https://doi.org/10.1007/s00431-019-03483-9

Publisher's Note Springer Nature remains neutral with regard to jurisdictional claims in published maps and institutional affiliations. 